\title{
A Cavity Ringdown Spectroscopy Mercury Continuous Emission Monitor
}

\author{
Quarterly Technical Progress Report
}

\author{
For the period \\ Starting October 1, 2001 Ending December 31, 2001
}

Work Performed Under Contract:

DE-FC26-01FT41221

Submitted By:

Sensor Research and Development Corporation

17 Godfrey Road

Orono, Maine 04473

Christopher C. Carter, Ph.D.

Phone Number: 207/866-0100 x239

Fax Number: 207/866-2055

Submitted To:

U. S. Department of Energy

Morgantown Energy Technology Center

Morgantown, West Virginia

COR: Susan Maley 


\title{
Disclaimer:
}

This report was prepared as an account of work sponsored by an agency of the United States Government. Neither the United States Government nor any agency thereof, nor any of their employees, makes any warranty, express or implied, or assumes any legal liability or responsibility for the accuracy, completeness, or usefulness of any information, apparatus, product, or process disclosed, or represents that its use would not infringe privately owned rights. Reference herein to any specific commercial product, process, or service by trade name, trademark, manufacturer, or otherwise does not necessarily constitute or imply its endorsement, recommendation, or favoring by the United States Government or any agency thereof. The view

and opinions of authors expressed herein do not necessarily state or reflect those of the United States Government or any agency thereof.

\begin{abstract}
:
The first quarter of this project to develop a Cavity Ringdown Spectroscopy mercury continuous emission monitor involved acquisition and verification of the laser system to be used, initial cavity design, and initial software development for signal processing and data acquisition.
\end{abstract}

\section{Table of Contents}

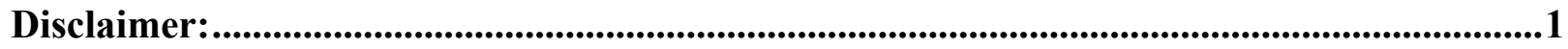

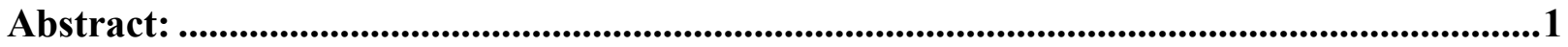

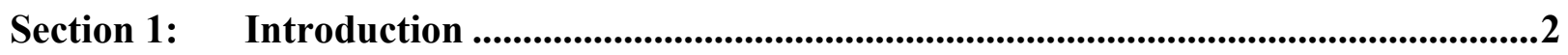

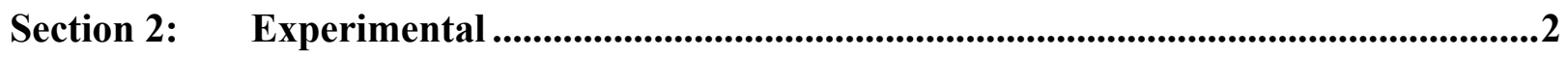

Section 3: $\quad$ Results and Discussion...........................................................................4

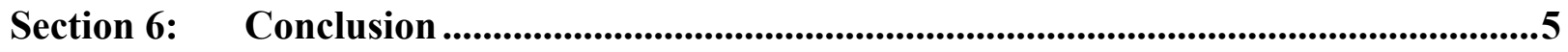

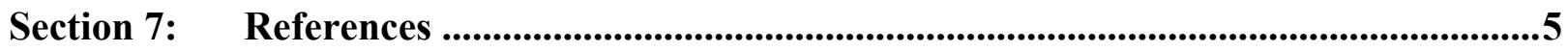




\section{Section 1: Introduction}

The objective of this project is an innovative science-driven technology program to develop a prototype instrument that exploits the full potential of cavity ringdown spectroscopy (CRD) as a powerful new analytical technique for the detection of ultra-trace levels of mercury.

The core effort focuses on the optimization and evaluation of a laboratory CRD spectrometer for gaseous mercury detection. Detection limits, calibration and appropriate analytical procedures will be established. The impact of interferent gases expected in advanced power plants will be determined, and approaches to determine mercury speciation will be investigated and demonstrated. A sampling interface will be designed, built, and integrated into the CRD spectrometer.

A summary of the major tasks is described below:

Task 1: Mercury CRDS System Development. Design and construct CRDS system for optimum mercury detection.

Task 2: Software Modification. Modify an existing LabView software package to analyze the data and control the $50 \mathrm{~Hz}$ laser and sampling system.

Task 3: Hg-CRDS System Optimization. Determine the optimum operating conditions of the spectrometer, establish the sensitivity of the technique in terms of detection limits, and evaluate the effect of typical interferents. Develop and test a mercury speciation system to insure detection of total mercury concentration.

Task 4: Sampling Interface. Design and build the sampling system for delivery of sample gas to and from the mercury speciation system.

Task 5: Integration of Sampling System. Combine sampling system and spectrometer and determine impact, if any, on the instruments performance.

Task 6: Formalize Hg-CRDS Analytical Procedures. Establish and formalize operating parameters and calibration procedures to provide validation of the results to meet the requirements necessary to allow comparison of the instrument performance with either EPA Reference 29 or the Ontario Hydro methods.

\section{Section 2: Experimental}

The experimental technique that will be used for this project is cavity ringdown spectroscopy (CRD). CRD is a sensitive absorption technique that was first developed by O'Keefe and Deacon in 1988. ${ }^{1}$ This technique injected a pulse of light into a stable optical cavity formed by two highly reflecting mirrors. The light reflects back and forth in the cavity giving extremely long effective pathlengths. Using mirrors with a reflectivity of $99.99 \%$ and a 1 meter long cavity it is possible to achieve an effective pathlength of 10 kilometers. As the light reflects back and forth in the cavity a small amount of light is transmitted through the end mirror of the cavity to a photon detector such as a photomultiplier tube. The light exiting the cavity decays exponentially with time at a rate determined by round trip loss mechanisms within the cavity. The measured time constant for the exponential decay of light is called the "ringdown time" of the cavity. The dominant loss mechanism for an empty cavity is the reflectivity of the mirrors. However if a sample species, which absorbs light at a particular wavelength, is placed within the cavity the ringdown 
time will decrease from that of the empty cavity at that particular wavelength. The ringdown time is given by

$$
\tau=\frac{l_{c}}{c\left[(1-R)+\alpha l_{s}\right]}
$$

where, $l_{c}$ is the cavity length, $R$ is the reflectivity of the mirrors, $\alpha$ is the absorption coefficient of the sample species of interest, and $l_{s}$ is the pathlength through the sample. Once the empty cavity losses have been determined, CRD spectroscopy provides an absolute measure of the concentration of the absorbing sample within the cavity. This self-calibrating feature differentiates CRD from other highly sensitive laser-based methods such as laser induced fluorescence (LIF) or resonantly enhanced multiphoton ionization (REMPI). ${ }^{2}$

The laser source that will be used for the project is a pulsed Alexandrite laser. This is a solid state laser that runs at $50 \mathrm{~Hz}$, will produce pulse energies of $>0.5 \mathrm{~mJ} /$ pulse at $253 \mathrm{~nm}$, and have a linewidth of 180 MHz. This laser pulse will be spatially filtered and mode matched to the cavity that will be used. Preliminary results indicate a cavity length of $56 \mathrm{~cm}$ is optimum for specially coated plano-concave mirrors with a $6 \mathrm{~m}$ radius of curvature. The actual absorption cell that will be used for the mercury detection will be placed between the highly reflecting mirrors.

The design of the CRD absorption cell will have an inlet for the sample containing mercury and exit for a continuous flow. There will also be a low flow of inert gas over the face of the highly reflecting mirrors to insure no degradation of the mirror surface. A diagram of the absorption cavity can be seen in Fig. 1.

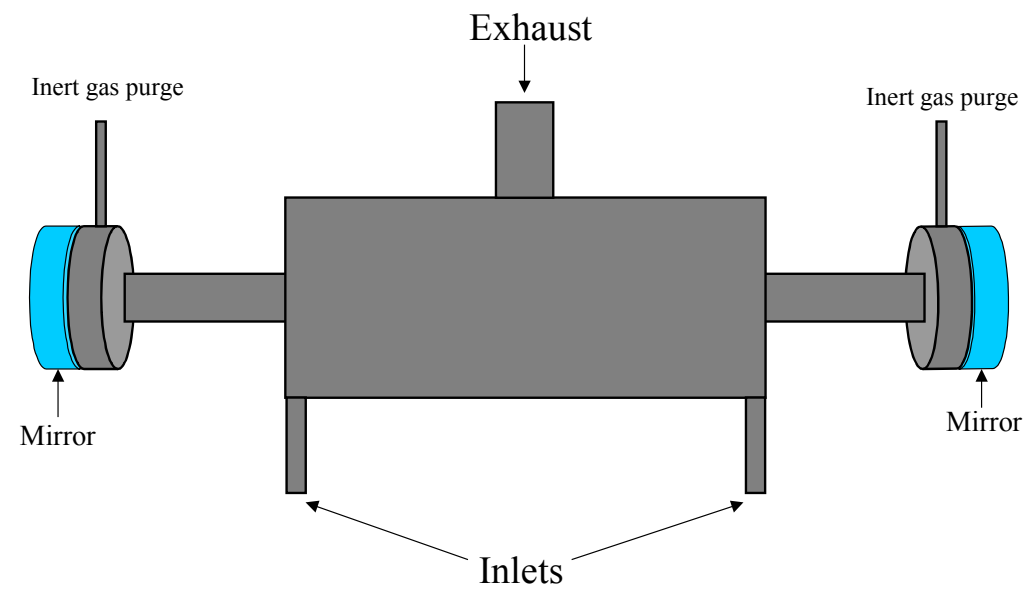

Figure 1: Diagram of sampling cavity (not done to scale) placed between the two highly reflecting mirrors

The data acquisition system will take the output of a photomultiplier tube and send it to a fast analog-todigital 12-bit, $100 \mathrm{MHz}$ card. A LabView program will be written for control of the laser system, data acquisition, and signal processing. The program will calculate the decay time of the ringdown curve, compare it with that for the empty cavity, and determine the absolute concentration of Mercury in the absorption cell at any time. 
A Mercury vapor generator will be coupled to the absorption cell. Mercury speciation studies will begin by using a pyrolizer system. The relative efficiency of the pyrolizer for dissociating different species of mercury will be evaluated using known quantities of substances such as elemental mercury, dimethyl mercury, and mercuric chloride.

In addition a dynacalibrator with a mercury permeation tube will be attached to the CRD system for periodic absolute calibration checks.

The following table lists the major milestones and their planned completion dates for the project.

\section{Section 3: Discussion}

\begin{tabular}{|l|c|c|}
\hline Milestone Description & Baseline & Actual \\
\hline 1. Finalize CRD design & $3 / 31 / 02$ & \\
\hline $\begin{array}{l}\text { 2. Integration of LabView } \\
\text { software for data acquisition }\end{array}$ & $3 / 31 / 02$ & \\
\hline $\begin{array}{l}\text { 3. Establish baseline properties } \\
\text { of CRD spectrometer }\end{array}$ & $3 / 31 / 02$ & \\
\hline $\begin{array}{l}\text { 4. Characterize and optimize } \\
\text { Hg detection }\end{array}$ & $12 / 31 / 02$ & \\
\hline $\begin{array}{l}\text { 5. Evaluate approaches to Hg } \\
\text { speciation }\end{array}$ & $9 / 30 / 03$ & \\
\hline $\begin{array}{l}\text { 6. Construct sampling system } \\
\text { for on-line CRD }\end{array}$ & $9 / 30 / 03$ & \\
\hline $\begin{array}{l}\text { 7. Integrate sampling system } \\
\text { with CRD spectrometer }\end{array}$ & $3 / 15 / 04$ & \\
\hline $\begin{array}{l}\text { 8. Establish calibration } \\
\text { procedure and operational } \\
\text { parameters }\end{array}$ & $3 / 15 / 04$ & \\
\hline
\end{tabular}

\section{Results and}

Initial acquisition of materials needed to begin the project has started. Design and construction of the CRD system is progressing. Software development for data analysis, laser system control, and the sampling system interface is underway.

The laser system needed for the CRD spectrometer has been installed at SRD. It has been verified to meet the linewidth and mode stability criteria for the project. The detection system, including the photomultiplier tube and fast digitizing card, have been purchased and setup. The high reflectivity mirrors needed for the CRD cavity have also been obtained. A cavity has been setup and a ring-down signal has already been detected. Concurrently software engineers at SRD are working on the data acquisition and signal processing software. This includes a plug-in for calculating the absolute absorbance from the measured ring-down time that has already been written.

A chronological listing of significant events and accomplishments is given in the table below. 


\begin{tabular}{|l|l|}
\hline Date & Description \\
\hline $10 / 01$ & Acquired and setup Alexandrite PAL ring laser system \\
\hline $10 / 01$ & Acquired high reflectivity mirrors needed for CRD cavity \\
\hline $10 / 01$ & Installed fast digitizing card for data acquisition \\
\hline $12 / 18 / 01$ & Setup CRD cavity \\
\hline $12 / 27 / 01$ & Produced 253 nm light from laser system needed for mercury detection \\
\hline $12 / 31 / 01$ & Coupled light into cavity and detected ringdown signal \\
\hline
\end{tabular}

\section{Section 6: Conclusion}

Current progress on the project has been rapid and with the acquisition of a ringdown signal the CRD cavity design can be finalized. This along with the software development will lead directly into establishing the empty cavity parameters and then mercury detection.

The first priority is finalizing the design of the CRD spectrometer. This will include integration of software for control of the laser system, which will allow frequency scans of the laser and automated data acquisition. Once in place the empty cavity parameters such as mirror reflectivity can be established that will provide the baseline necessary for mercury detection.

\section{Section 7: $\quad$ References}

1. A. O'Keefe and D. A. G. Deacon, "Cavity ring-down optical spectrometer for absorption measurements using pulsed laser sources" Rev. Sci. Intstrum. 59 (12), 2544-2551 (1988).

2. G. Berden, R. Peeters, and G. Meijer, "Cavity ring-down spectroscopy: Experimental schemes and applications" Int. Rev. Phys. Chem. 19 (4), 565-607 (2000). 